\title{
Mediation of Endogenous $\beta$-Endorphin in the Plasma Glucose-Lowering Action of Herbal Products Observed in Type 1-Like Diabetic Rats
}

\author{
I. M. Liu' ${ }^{1}$ and J. T. Cheng ${ }^{2}$ \\ ${ }^{1}$ Department of Pharmacy, Tajen University, Yen-Pou, Ping Tung Shien, Taiwan \\ ${ }^{2}$ Department of Pharmacology, College of Medicine, National Cheng Kung University, Tainan City, Taiwan
}

Correspondence should be addressed to J. T. Cheng, jtcheng@mail.ncku.edu.tw

Received 4 September 2008; Accepted 14 November 2008

Copyright ( $\odot 2011$ I. M. Liu and J. T. Cheng. This is an open access article distributed under the Creative Commons Attribution License, which permits unrestricted use, distribution, and reproduction in any medium, provided the original work is properly cited.

\begin{abstract}
Recently, there have been advances in the development of new substances effective in managing diabetic disorders. Opioid receptors couple multiple systems to result in various biological effects, although opioids are best known for analgesia. In the present review, we used our recent data to describe the advance in plasma glucose-lowering action of herbal products, especially the mediation of $\beta$-endorphin in glucose homeostasis of insulin-deficient diabetes. In type 1-like streptozotocin-induced diabetic rats, we identified many products purified from herbs that show a dose-dependent plasma glucose-lowering action. Increase in $\beta$-endorphin secretion from the adrenal gland may activate peripheral opioid $\mu$-receptors (MOR) to enhance the expression of muscle glucose transporters and/or to reduce hepatic gluconeogenesis at the gene level, thereby leading to improved glucose utilization in peripheral tissues for amelioration of severe hyperglycemia. It has also been observed that stimulation of $\alpha_{1}$-adrenoceptors $\left(\alpha_{1}\right.$-ARs) in the adrenal gland by some herbal products is responsible for the increase in $\beta$-endorphin secretion via a phospholipase C-protein kinase dependent pathway. However, an increase in $\beta$-endorphin secretion from the adrenal gland by herbal products can function via another receptor. New insights into the mediation of endogenous $\beta$-endorphin activation of peripheral MOR by herbal products for regulation of glucose homeostasis without the presence of insulin have been established. Therefore, an increase in $\beta$-endorphin secretion and/or direct stimulation of peripheral MOR via an insulin-independent action might serve as the potential target for development of a therapeutic agent or promising adjuvant in intensive plasma glucose control.
\end{abstract}

\section{Introduction}

Diabetes mellitus, which ranks among the top 10 causes of mortality in the world, is a metabolic disease characterized by abnormally high levels of glucose in the blood and/or urine. This metabolic disorder often leads to disability from vascular complications, including coronary artery disease, cerebrovascular disorder, renal failure, blindness and limb amputation, in addition to neurologic complications and premature death [1]. In order to normalize the plasma glucose level, dietary restrictions, exercise and oral glucoselowering agents are widely used [2].

A widely recommended approach for the control of hyperglycemia is to administer a parenteral insulin preparation that provides a constant addition of circulating insulin for $12-24 \mathrm{~h}$ to augment or replace the deficient endogenous insulin secretion $[3,4]$, although insulin resistance is initially recognized in insulin-treated patients. Like other hormonesensitive pathways, the intracellular pathway of insulin action is continuously being regulated by multiple influences. Continuous exposure to insulin causes a reduction in the number of receptors on the cell surface by promoting internalization as well as degradation of hormone-occupied receptors [5]. The insulin receptor is linked with tyrosine kinase that activates itself and then transmits its stimulatory message after the phosphorylation of selected tyrosine. During continuous exposure to insulin, the kinase activity of the receptor is diminished as a result of combined effects of various factors [6-8]. Also, chronic exposure of the cell to insulin may result in a diminished concentration of downstream elements, including insulin receptor substrate proteins [8]. The mechanisms underlying the concentration- and time-dependent 
induction of insulin resistance are complex and incompletely defined. Thus, it is imperative to provide new targets achieving equal and/or superior effects on insulin to control glycemia with less insulin resistance.

Opioid receptors are coupled to multiple systems and play a role in various biological effects, including analgesia, miosis, bradycardia, general sedation, hypothermia, insensitivity and depression of flexor reflexes [9]. Opiods have a well-known role in lowering pain [10], in addition to modulation of the immune system and endocrine processes [11]. The peripheral effect of opiates on glucose homeostasis through pancreatic islet hormone secretion has also been documented $[12,13]$. The opioid peptide, $\beta$-endorphin, has been shown to regulate insulin, glucagon, and somatostatin release from isolated Langerhans islets [14-16]. In addition to the finding that $\beta$-endorphin can inhibit glucose production in conscious dogs, $\beta$-endorphin has an ability to increase insulin secretion via activation of opioid receptors located in pancreatic $\beta$-cells $[17,18]$. From the effect of opioids on glucose homeostasis, opioids or opioid receptor activation may have merit in glycemic control. However, the effect of opioids on glucose metabolism in the absence of insulin remains obscure.

Recently, we provided a new evidence that activation of peripheral opioid $\mu$-receptors (MOR) might modify glucose metabolism-associated genes to improve glucose utilization and reduce hepatic gluconeogenesis, thus leading to a decrease in high plasma glucose in streptozotocin-induced diabetic rats (STZ-diabetic rats). The deficient function of pancreatic $\beta$-cells in STZ-diabetic rats has been documented and rats with STZ-induced diabetes are widely used as an animal model of type 1-like diabetes [19]. The effect of opioids on glucose homeostasis in type 1-like diabetic rats may in fact be produced by mechanisms other than insulin. Currently, there is an enormous increase in the application of herbal and other alternative medicines for the treatment of diabetic disorders. Thus, chemical compounds or herbal products with the ability to enhance $\beta$-endorphin secretion and/or peripheral MOR activation, but not an opiate-like central nervous effect, might be valuable as a therapeutic intervention or an attractive adjuvant for diabetic disorders. Herein, we describe recent advances in insulin-independent mechanism(s) of herbal products in the management of glucose metabolism in insulin-deficient diabetes.

\section{Endogenous $\beta$-Endorphin Participates in the Plasma Glucose-Lowering Action in an Insulin-Deficient State}

2.1. Roles of Endogenous Opioids on Glucose Homeostasis. Previous studies have demonstrated that different forms of stress activate the endogenous opioid system, which in turn contributes to the changes in systemic cardiovascular function and endocrine responses occurring under these conditions [20-22]. Exposure to a cold environment may increase sympathetic nervous activity, inducing an elevation of plasma norepinephrine (NE) and result in hyperglycemia [23]. However, in STZ-diabetic rats, the plasma glucoselowering response is observed after cold exposure at $4^{\circ} \mathrm{C}$ for
$1 \mathrm{~h}$ with an elevation of $\beta$-endorphin-like immnoreactivity (BER) in plasma, which does not occur in normal rats [24]. The decrease in plasma glucose and increase of BER in response to cold stress are blocked by prazosin at a dose sufficient to abolish $\alpha_{1}$-adrenoceptors (ARs) activity. Also, the lowering of plasma glucose in STZ-diabetic rats by cold stress is abolished in the presence of a naloxone dose sufficient to block opioid receptors. Opioid receptor activation thus appears to be related to the plasma glucoselowering action of cold stress in STZ-diabetic rats.

Although many physiologic actions of endogenous $\beta$ endorphin are recognized to be mediated by MOR, including the regulation of plasma glucose $[25,26]$, mediation of opioid $\delta$-receptors (located on skeletal muscles) in the hypoglycemic effect of BER has been demonstrated [27-29]. We used MOR knockout mice to verify that MOR are involved in the regulation of plasma glucose in the absence of insulin [30]; the plasma glucose-lowering response to cold stress was not present in STZ-diabetic mice lacking MOR. Also, exogenous $\beta$-endorphin induced plasma glucose-lowering activity was abolished in MOR knockout STZ-diabetic mice [30]. Therefore, activation of MOR appears to be responsible for the plasma glucose-lowering response to cold stress in insulin-deficient diabetic animals.

2.2. Activation of $\alpha$-ARs in the Adrenal Medulla Enhance $\beta$ Endorphin Secretion in an Insulin-Deficient State. Although $\beta$-endorphin is released along with adrenocorticotrophic hormone from the pituitary gland [31], the presence of endogenous opioids in the adrenal medulla has been identified in several species [32-35]. Various forms of polypeptides that cross-react with opioid antisera are stored together with catecholamines and soluble proteins in the granules of the adrenal gland. Bilateral adrenalectomy abolishes the plasma glucose-lowering response to cold stress in type 1like diabetic animals [30]. Therefore, activation of MOR by opioids from the adrenal gland appears to be responsible for the plasma glucose-lowering response to cold stress in diabetic animals with insulin deficiency.

The binding site of $\alpha_{1}$-ARs in theadrenal medulla has been observed [36]. We have demonstrated that pharmacologic manipulation with methoxamine, an agonist of $\alpha_{1}$ ARs, reduced plasma glucose along with an elevation of plasma BER in STZ-diabetic rats, but a similar elevation of plasma BER by methoxamine has not been observed in normal rats [24]. A dose-dependent increase in plasma NE and $\beta$-endorphin has been demonstrated in STZ-diabetic rats receiving prostaglandin $(\mathrm{PG}) \mathrm{E}_{2}$ injections, and these $\mathrm{PGE}_{2}$-induced actions are blocked by prazosin at a dose sufficient to abolish $\alpha_{1}$-ARs effects [37]. We also observed that phenylephrine enhances BER secretion from isolated adrenal medulla of Wistar rats in a concentration-dependent manner and this action is abolished by prazosin [38]. Secretion of $\beta$-endorphin from the adrenal glands of insulindeficient hyperglycemic rats in response to $\alpha_{1}$-ARs activation is further supported by the finding that the plasma glucoselowering action of $\mathrm{PGE}_{2}$ is deleted in STZ-diabetic rats undergoing bilateral adrenalectomy and no increase in plasma $\beta$-endorphin results in these rats even at highest doses 
of $\mathrm{PGE}_{2}$ [37]. Activation of $\alpha_{1}$-ARs in the adrenal medulla for the regulation of endogenous opioid secretion should thus be considered. Indeed, our data support that pituitary gland-independent release of endogenous opioids is exists in peripheral organs [39-41].

2.3. Signals for the Increase of $\beta$-Endorphin Secretion after Activation of $\alpha$-ARs in the Adrenal Medulla. It has been established that $\alpha_{1}$-ARs belong to the family of G protein-coupled receptors which initiate signals by activating phospholipase C (PLC)-dependent hydrolysis of phisphatidylinositol 4,5 biphosphate $[41,42]$. This enzyme may generate the second messengers, inositol-1,4,5-triphosphate (which releases $\mathrm{Ca}^{2+}$ from intracellular stores) and diacylglycerol (DAG; which synergizes with $\mathrm{Ca}^{2+}$ to activate protein kinase $\mathrm{C}$ (PKC) [41, 42]. U73122, an aminosteroid derivative, has widely been used as a specific inhibitor of PLC [43]. After comparison with its negative control, U73343 [44], the response sensitive to this inhibitor can be identified as an activation of membrane-bound PLC. It has been demonstrated that U73122 abolishes phenylephrine-stimulated BER secretion from the rat adrenal medulla, but U73343, the negative control, failed to modify this action of phenylephrine [38]. The role of PKC in the increase of BER secretion by $\alpha_{1}$ ARs in the rat adrenal medulla has also been characterized by using chelerythrine [45] and GF 109203X [46] because both compounds inhibit PKC in a competitive manner with respect to the phosphate acceptor. Indeed, the action of phenylephrine to stimulate BER secretion from isolated rat adrenal medulla is attenuated by chelerythrine or GF 109203X in a concentration-dependent manner. This survey showed the involvement of the PLC-PKC pathway in the activation of $\alpha_{1}$-ARs related to the higher secretion of $\beta$ endorphin from the adrenal gland.

Multiple subtypes of $\alpha_{1}$-ARs have been characterized and the receptor is classified into three native subtypes $\left(\alpha_{1 \mathrm{~A}}, \alpha_{1 \mathrm{~B}}\right.$ and $\left.\alpha_{1 \mathrm{D}}\right)$ with corresponding cloned counterparts $\left(\alpha_{1 \mathrm{a}}, \alpha_{1 \mathrm{~b}}\right.$ and $\left.\alpha_{1 \mathrm{~d}}\right)$ [47-51]. It has been demonstrated that phenylephrine-stimulated $\beta$-endorphin secretion in isolated rat adrenal medulla is attenuated by pretreatment with tamsulosin [38]. Although tamsulosin acts on both $\alpha_{1 \mathrm{~A}}$-AR and $\alpha_{1 \mathrm{D}}-\mathrm{AR}$, this compound is more selective for the $\alpha_{1 \mathrm{~A}^{-}}$ subtype [52]. Thus, activation of $\alpha_{1}$-ARs, especially the $\alpha_{1 \mathrm{~A}}$ subtype, on the adrenal medulla of insulin-deficient animals, may enhance the secretion of endogenous $\beta$-endorphin to regulate plasma glucose homeostasis. However, the subtype of $\alpha_{1}$-ARs presenting in the adrenal medulla has not been clearly identified and requires clarification.

\subsection{Higher $\beta$-Endorphin Biosynthesis in the Adrenal Gland} under an Insulin-Deficient State. Pro-opiomelanocortin (POMC), the precursor to $\beta$-endorphin and several other peptides, is synthesized by the following two groups of central neurons: (i) the arcuate nucleus and adjacent regions of the medial basal hypothalamus and (ii) the commissural subnucleus of the nucleus tractus solitarius [53]. The presence of endogenous opioids in the adrenal gland has been identified in several species $[32,34,35,54]$. We observed that POMC gene expression is elevated, which is related to an increase of $\beta$-endorphin in the adrenal glands, resulting in higher plasma BER in STZ-diabetic rats as compared to normal rats [55]. Otherwise, a decrease in POMC mRNA level has been reported in the pituitary, but no change in the whole hypothalamus of diabetic rats [56]. In contrast, an increase in POMC mRNA level in the thymus is evident in STZ-diabetic rats, while gene expression of POMC in the spleen is unaltered [57]. This may be due to tissue difference. Nevertheless, an increase of $\beta$-endorphin synthesis in insulin-deficient diabetic rats supports a higher response to activate the opioid system for lowering plasma glucose.

\section{Peripheral MOR Activation Participates in the Plasma Glucose-Lowering Action in an Insulin-Deficient State}

3.1. Increase of Peripheral MOR Gene Expression in an InsulinDeficient State. In our previous study, a dose-dependent lowering of plasma glucose was observed in the fasting STZdiabetic rat $15 \mathrm{~min}$ after intravenous injection of exogenous $\beta$-endorphin; this action was abolished by pretreatment with naloxone or naloxonazine at doses sufficient to block MOR [58]. Also, agonists of MOR, including loperamide and tramadol, lower plasma glucose in STZ-diabetic rats, and this action was neutralized by $\operatorname{MOR}$ blockade $[59,60]$. In contrast, the MOR activation-induced plasma glucoselowering effect was not easy to obtain in animals with normal insulin action. It seems that a higher response to MOR activation might be responsible in diabetic rats lacking insulin. Many studies have indicated that diabetes or hyperglycaemia alter the sensitivity of animals to various agents $[61,62]$. It has also been demonstrated that diabetic animals are more sensitive than normal controls to the hyperphagic effect of agonists specific to MOR [63]. However, diabetic animals are less sensitive than normal controls to anti-nociceptive action mediated by supraspinal $\operatorname{MOR}[64,65]$. In addition to the parameter of neuropathy in diabetic disorders [66], this may be due to the difference between the central nervous system and peripheral tissues, while little information is available regarding the change of MOR in diabetic disorders. It has been shown that the expression of $\beta$-endorphin action receptor on skeletal muscle is vastly increased in type 1 and type 2 diabetic animals $[67,68]$. Our previous reports indicated that an increase in MOR not only existed in skeletal muscle, but the higher protein level of this receptor was also observed in the liver of STZ-diabetic rats [69]. Therefore, both the amount of opioid and the gene expression of MOR were raised in STZ-diabetic rats.

3.2. Activation of Peripheral MOR Enhances an Increase of Glucose Utilization under an Insulin-Deficient State. Using the intravenous glucose challenge test (IVGCT) that is available to characterize the ability of animals to clear glucose from the circulation, we observed that an intravenous injection of loperamide at a dose which activates MOR $\left(17.6 \mu \mathrm{g} \mathrm{kg}^{-1}\right)$ significantly attenuates the increase of plasma glucose induced by IVGCT in STZ-diabetic rats 
[59]. Activation of peripheral MOR may increase glucose utilization to ameliorate hyperglycemia under the absence of insulin should be considered.

Glucose uptake or transportation depending on insulinstimulated translocation of glucose carriers to the cell membrane belongs to the rate-limiting step in carbohydrate metabolism of skeletal muscle, a major site for glucose disposal [70]. Under basal conditions, the rate of glucose uptake into skeletal muscle is low and insulin-stimulated glucose disposal is believed to be the major regulation of plasma glucose concentration [70]. Hyperglycemia is an abnormal metabolic state characterized by a marked insulin defect in muscle [71]. We demonstrated that $\beta$-endorphin causes an increase in glucose uptake in isolated soleus muscles of STZ-diabetic rats to lower plasma glucose and this effect is antagonized by MOR-specific blockers [58]. The stimulatory effects of loperamide and tramadol on glucose uptake have also been shown in soleus muscles isolated from STZ-diabetic rats and the effects are blocked by an inhibitor specific to MOR $[60,72]$. Thus, activation of peripheral MOR results in an increase in glucose uptake into skeletal muscle and is related to the lowering of plasma glucose under an insulin-deficient state.

The liver is also responsible for the regulation of blood glucose through its ability to store glucose as glycogen and/or to produce glucose from glycogen breakdown or gluconeogenic precursors [73]. In diabetes, elevation of blood glucose is a consequence of increased hepatic glucose output together with reduced peripheral glucose utilization [74]. We have observed that both naloxone and naloxonazine, at concentrations sufficient to block MOR, inhibit the increase in glycogen synthesis in STZ-diabetic rats [58, 60, 72]. Therefore, an increase in glucose utilization through peripheral MOR activation can be considered as one of the mechanism(s) for regulation of plasma glucose in the absence of insulin.

3.3. Signals for the Increase in Glucose Uptake by Peripheral MOR Activation. Opioid receptor activation couples a number of intracellular signaling pathways, including the mediation of PLC and PKC activation [75]. The uptake of radioactive glucose into isolated soleus muscle induced by $\beta$-endorphin is abolished by U73312, the specific inhibitor of PLC, while it is not affected by U73343, the negative control of U73312 [58]. Moreover, chelerythrine and GF 109203X diminished the stimulatory effect of $\beta$-endorphin on radioactive glucose uptake into isolated soleus muscle at a concentration sufficient to inhibit PKC [58]. The linkage of MOR and the PLC-PKC pathway in the regulation of glucose uptake is further characterized using the blockade of loperamide-stimulated 2-DG uptake in $\mathrm{C}_{2} \mathrm{C}_{12}$ cells by the inhibitors specific for PLC or PKC [76]. The data suggest that activation of MOR may increase glucose uptake in peripheral tissues via the PLC-PKC pathway to lower plasma glucose in diabetic rats lacking insulin.

A family of glucose transporters (GLUT) mediates glucose transport across the cell membrane, while the subtype 4 form (GLUT 4) is predominant in skeletal muscle [77].
Reduction in insulin-mediated glucose uptake caused by lower gene expression of GLUT 4 in diabetes has been observed $[71,78]$. It has been reported that PKC is involved in the rate-limiting step in GLUT gene expression [79]. The gene expression of GLUT 4 in soleus muscles of STZ-diabetic rats is increased by loperamide after repeated injection for 3 days [72]. Activation of MOR by tramadol to increase glucose uptake into isolated soleus muscles with an elevation of GLUT 4 gene expression in STZ-diabetic rats has also been observed [60]. Therefore, the PLC-PKC pathway is linked to peripheral MOR activation for regulation of muscle GLUT 4 gene expression.

3.4. Decrease of Hepatic Gluconeogenesis by Peripheral MOR Activation in Insulin-Deficient State. Phosphoenolpyruvate carboxykinase (PEPCK; EC 4.1.1.32), the main catalyzing enzyme in gluconeogenesis, has widely been studied in hepatic carbohydrate metabolism [80, 81]. Studies in diabetic animals have shown that augmented gluconeogenesis is a major factor in the increase in plasma glucose that appears in fasting and post-absorptive states [74]. Downregulation of the PEPCK gene might be associated with a decrease in hepatic gluconeogenesis to result in the lowering of plasma glucose. We observed that loperamide at the dose which is effective in activating MOR, decreased the plasma glucose of STZ-diabetic rats accompanied by a marked reduction of PEPCK gene expression in the liver [72]. Similarly, an increased expression of the hepatic PEPCK gene in STZdiabetic rats is reversed by tramadol [60]. Thus, peripheral MOR activation might act as a negative regulator to influence hepatic PEPCK gene expression and ameliorate the severe hyperglycemia in animals with insulin insufficiency. Gene expression of hepatic PEPCK is regulated by a number of hormones [81, 82], but signals for insulin to inhibit PEPCK expression are not transmitted through the PKC pathway [82]. Nevertheless, the decline in hepatic gluconeogenesis for lowering of plasma glucose mediated by peripheral MOR activation in the absence of insulin has been established.

\section{Mediation of Endogenous $\beta$-Endorphin in the Plasma Glucose-Lowering Action of Herbal Products}

4.1. Herbal Products Directly Activate $\alpha A-A R s$ on Adrenal Glands to Increase $\beta$-Endorphin Secretion. Modern medicine is believed to be the best treatment approach for acute conditions. However, Traditional Chinese medicine (TCM) is based on natural plants and such comprehensive and flexible treatment strategies always bring about fantastic treatment results. Recently, for the treatment of chronic conditions, most modern people prefer green and safe medicine and this tendency is becoming more and more prominent. Thus, people in the world are interested in TCM and it is gradually becoming mainstream medicine. Currently, there is an enormous increase in the application of herbs and other alternative medicines for the treatment of diabetic disorders. However, the mechanisms for these treatments remain unclear. Based on our previous studies, 
TABLE 1: Herbal products exert plasma glucose-lowering action via $\beta$-endorphin secretion or activation of peripheral MOR in type 1-like diabetic animals

\begin{tabular}{|c|c|c|}
\hline Herbal products & Chemical names & $\begin{array}{l}\text { Insulin-independent plasma glucose-lowering } \\
\text { mechanisms }\end{array}$ \\
\hline Caffeic acid & 3,4-Dihydroxycinnamic acid [83-85] & $\begin{array}{l}\text { Activation of } \alpha 1 \text {-ARs on adrenal glands to increase } \\
\beta \text {-endorphin secretion; the released } \beta \text {-endorphin } \\
\text { then stimulates peripheral MOR leading to enhance } \\
\text { glucose uptake and attenuate hepatic } \\
\text { gluconeogenesis }\end{array}$ \\
\hline Isoferulic acid & 3-Hydroxy-4-methoxycinnamic acid [86-89] & \\
\hline Puerarin & 4',7-Dihydroxy-8-C-glucosylisoflavone [90-92] & \\
\hline Andrographolide & 2.4.5.7-Trihydroxyflavone [93-95] & \\
\hline Myricetin & $3,3^{\prime}, 4^{\prime}, 5,5^{\prime}, 7-$ Hexahydroxyflavone $[96,97]$ & $\begin{array}{l}\text { The insulin-independent plasma glucose-lowering } \\
\text { action of these compounds was induced by } \\
\text { activation of peripheral MOR via released } \\
\beta \text {-endorphin, while the receptor mediated on the } \\
\text { enhancement of adrenal } \beta \text {-endorphin secretion is } \\
\text { still unclear. }\end{array}$ \\
\hline Ginsenoside $\mathrm{Rh} 2$ & Proto-panaxadiol-3-o- $\beta$-D-glucopyranoside [98] & \\
\hline Syringin & $\begin{array}{l}\text { 4-(3-hydroxy-1-propenyl)-2,6-dimethoxyphenyl } \\
{[99,100]}\end{array}$ & \\
\hline
\end{tabular}

here, we indicated that some herbal products possess the plasma glucose-lowering property mediated by $\beta$-endorphin in the absence of insulin.

Hydroxycinnamic acids, such as caffeic acid (3,4-dihydroxycinnamic acid), ferulic, acid (4-hydroxy-3-methoxycinnamic acid) and isoferulic acid (3-hydroxy-4-methoxycinnamic acid) (Table 1) are present in a large variety of fruits and vegetables, including blueberries, grapes, apples, cereal bran, broccoli, spinach and lettuce [101]. Hydroxycinnamic acid derivatives have been reported to show numerous biological activities, such as antioxidant activity, suppression of interleukin-8 production, interaction with oxytocin, inhibition of 5-lipoxygenase, effect on the arachidonic acid cascade, and anti-inflammatory activity [102-105]. The potential effect of hydroxycinnamic acid derivatives on glucose metabolism in insulin-deficient rats has also been demonstrated; activation of $\alpha_{1 \mathrm{~A}}$-ARs in adrenal medulla by caffeic acid [83-85] and isoferulic acid [86-89] enhance the secretion of $\beta$-endorphin from the adrenal glands of STZdiabetic rats (Table 1, Figure 1). Thus, hydroxycinnamic acid derivatives might serve as adjuvants for amelioration of high plasma glucose in patients with diabetes.

Traditionally, puerarin, a naturally occurring isoflavone $\mathrm{C}$-glycoside, is used to reduce febrile symptoms, dilate arterial coronary and cerebral vessels, and decrease myocardial consumption of oxygen [106-109]. In addition, andrographolide belongs to the diterpene lactones, and has been reported to have multiple pharmacologic properties, such as protozoacidal activity, inhibition of platelet aggregation, inhibition of protein convertases- 1 and -7 , and furin, stimulation of cell differentiation, and anti-hepatotoxic activity, and may be developed as the drug for treatment of tissue injury, septic shock, and autoimmune diseases [110-115]. We found that puerarin [90-92] and andrographolide [9395] also posses the ability to activate $\alpha_{1}$-ARs, especially the $\alpha_{1 \mathrm{~A}}$-subtype, to enhance $\beta$-endorphin secretion from adrenal glands of STZ-diabetic rats (Table 1, Figure 1). Thus, these compounds possess plasma glucose-lowering property without insulin.

4.2. Other Herbal Products with the Ability to Increase $\beta$ Endorphin Secretion. An increase in $\beta$-endorphin secretion by herbal products does not depend on activation of $\alpha_{1}$ ARs only. The plasma glucose-lowering action of myricetin, a naturally occurring flavonoid, is commonly found in tea, berries, fruits, vegetables and the medicinal herb, mediated by activation of $\alpha_{1}$-ARs to increase the release of $\beta$-endorphin in type 1-like diabetic rats is not be defined [96, 97]. Although mediation of $\beta$-endorphin by ginsenoside $\mathrm{Rh} 2$, one of the ginsenosides contained in Panax ginseng root, or by syringin of Eleutherococcus senticosus to lower plasma glucose in STZ-diabetic rats have been demonstrated, the mediated receptors of the compounds remain to be identified [98100]. Therefore, the insulin-independent plasma glucoselowering action of herbal products is not simple and needs more investigations.

\section{Conclusions}

Taken together, the findings of our study provide new insight into the roles of both $\alpha_{1}$-ARs and MOR in glucose homeostasis in insulin-deficient diabetes. In the adrenal gland, $\alpha_{1}$-ARs activation may increase $\beta$-endorphin secretion via the PLC-PKC pathway, which in turn activates peripheral MOR to modify gene expression associated with glucose metabolism, including muscle GLUT 4 and hepatic PEPCK, thereby leading to improved peripheral glucose utilization and decreased hepatic gluconeogenesis for amelioration of severe hyperglycemia in type 1-like diabetes (Figure 1). Thus, chemical compounds or herbal products that could enhance 


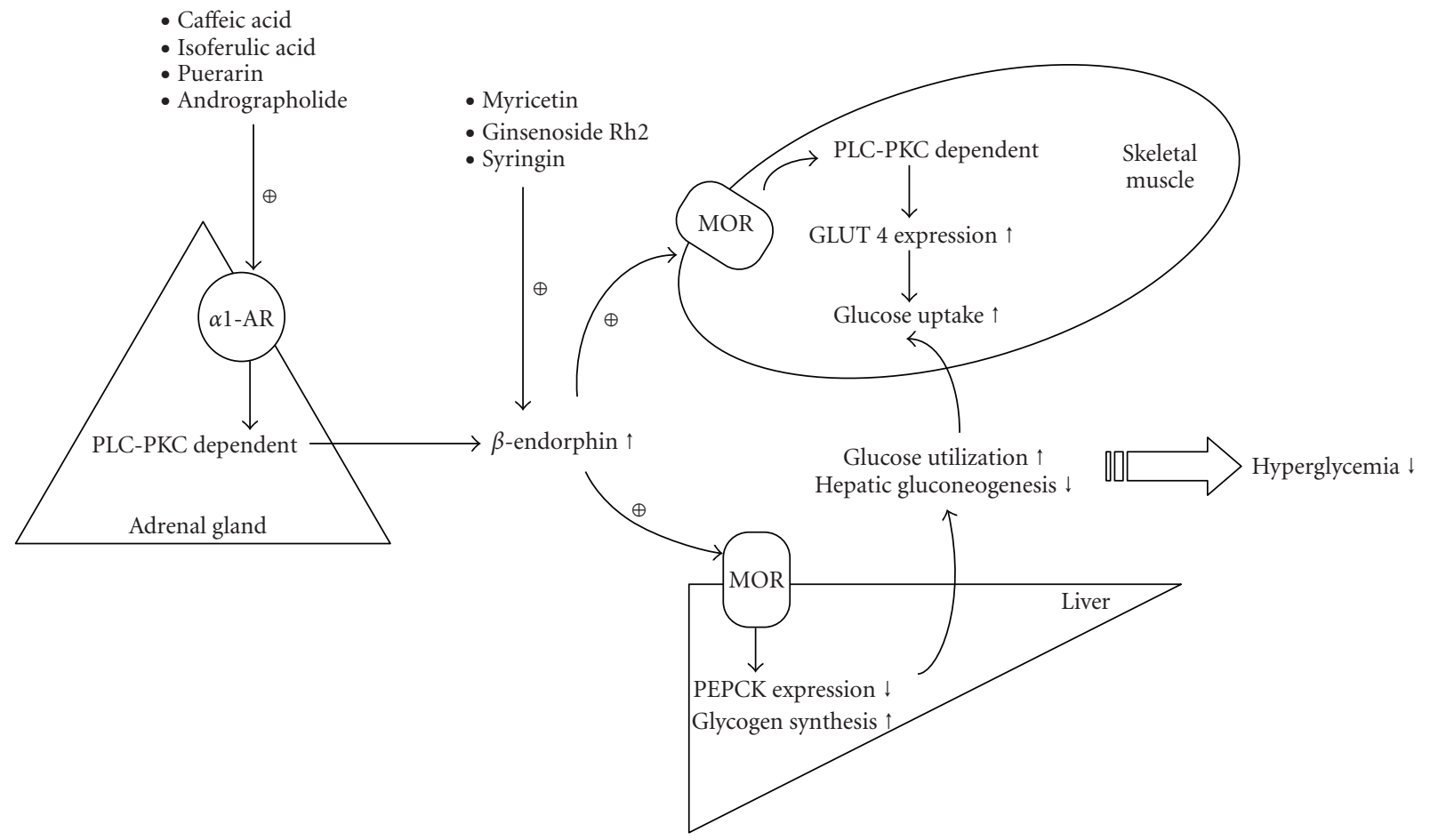

FIGURE 1: The possible mechanisms of herbal products on the plasma glucose-lowering action are mediated by activation of adrenal $\alpha_{1}$-ARs and/or stimulation of peripheral MOR in the absence of insulin. Activation of $\alpha 1$-ARs to increase $\beta$-endorphin release from adrenal gland was involved in the insulin-independent plasma glucose-lowering action of caffeic acid, isoferulic acid, puerarin and andrographolide. The receptor mediated on the adrenal $\beta$-endorphin secretion induced by myricetin, ginsenoside Rh 2 and syringin is not clear, but the insulinindependent plasma glucose-lowering activity of these compounds were induced by activation of peripheral MOR via released $\beta$-endorphin.

$\beta$-endorphin secretion and/or stimulate peripheral MOR might serve as a potential agent or an attractive adjuvant for targeting plasma glucose control without insulin. However, this result seems related to the absence of insulin and is different with the changes in normal animals. Also, mediation of other opioid peptides in the activation of peripheral MOR for plasma glucose-lowering actions in diabetic animal cannot be ruled out.

\section{References}

[1] S. L. Jeffcoate, "Diabetes control and complications: the role of glycated haemoglobin, 25 years on," Diabetic Medicine, vol. 21, no. 7, pp. 657-665, 2004.

[2] J. Lindström, A. Louheranta, M. Mannelin et al., "The Finnish Diabetes Prevention Study (DPS): lifestyle intervention and 3-year results on diet and physical activity," Diabetes Care, vol. 26, no. 12, pp. 3230-3236, 2003.

[3] H. Shamoon, H. Duffy, N. Fleischer et al., "The effect of intensive treatment of diabetes on the development and progression of long-term complications in insulin-dependent diabetes mellitus," The New England Journal of Medicine, vol. 329, no. 14, pp. 977-986, 1993.

[4] P. Reichard, B. Y. Nilsson, and U. Rosenquist, "The effect of long-term intensifie $\mathrm{d}$ insulin treatment on the development of microvascular complications of diabetes mellitus," The New England Journal of Medicine, vol. 329, pp. 304-309, 1993.

[5] J. R. Gavi III, J. Roth, and D. M. Neville Jr., "Insulin dependent regulation of insulin receptor concentrations: a direct demonstration in cell culture," Proceedings of the National Academy of Sciences of the United States of America, vol. 71, no. 1, pp. 84-88, 1974.

[6] Y. Zick, G. Grunberger, and J. M. Podskalny, "Insulin stimulates phosphorylation of serine residues in soluble insulin receptors," Biochemical and Biophysical Research Communications, vol. 116, no. 3, pp. 1129-1135, 1983.

[7] J. Kusari, K. A. Kenner, K.-I. Suh, D. E. Hill, and R. R. Henry, "Skeletal muscle protein tyrosine phosphatase activity and tyrosine phosphatase $1 \mathrm{~B}$ protein content are associated with insulin action and resistance," Journal of Clinical Investigation, vol. 93, no. 3, pp. 1156-1162, 1994.

[8] Y. Zick, "Insulin resistance: a phosphorylation-based uncoupling of insulin signaling," Trends in Cell Biology, vol. 11, no. 11, pp. 437-441, 2001.

[9] E. Chevlen, "Opioids: a review," Current Pain and Headache Reports, vol. 7, no. 1, pp. 15-23, 2003.

[10] T. L. Yaksh, "Pharmacology and mechanisms of opioid analgesic activity," Acta Anaesthesiologica Scandinavica, vol. 41, no. 1, pp. 94-111, 1997.

[11] E. M. Smith, "Opioid peptides in immune cells," Advances in Experimental Medicine and Biology, vol. 521, pp. 51-68, 2003.

[12] N. Eigler, L. Sacca, and R. S. Sherwin, "Synergistic interactions of physiologic increments of glucagon, epinephrine, and cortisol in the dog. A model for stress-induced hyperglycemia," Journal of Clinical Investigation, vol. 63, no. 1, pp. $114-123,1979$.

[13] C. H. Li, D. Chung, and B. A. Doneen, "Isolation, characterization and opiate activity of $\beta$ endorphin from human 
pituitary glands," Biochemical and Biophysical Research Communications, vol. 72, no. 4, pp. 1542-1547, 1976.

[14] D. Giugliano, D. Cozzolino, T. Salvatore, A. Ceriello, and R. Torella, "Dual effect of beta-endorphin on insulin secretion in man," Hormone and Metabolic Research, vol. 19, no. 10, pp. 502-503, 1987.

[15] X. Z. Khawaja and I. C. Green, "Dual action of betaendorphin on insulin release in genetically obese and lean mice," Peptides, vol. 12, no. 2, pp. 227-233, 1991.

[16] G. Paolisso, D. Giugliano, and A. J. Scheen, "Primary role of glucagon release in the effect of $\beta$-endorphin on glucose homeostasis in normal man," Acta Endocrinologica, vol. 115, no. 2, pp. 161-169, 1987.

[17] P. M. Radosevich, P. E. Williams, and J. M. McRae, " $\beta$ endorphin inhibits glucose production in the conscious dog," Journal of Clinical Investigation, vol. 73, no. 4, pp. 1237-1241, 1984.

[18] D. L. Curry, L. L. Bennett, and C. H. LI. , "Stimulation of insulin secretion by beta-endorphins ((1-27) \& (1-31))," Life Sciences, vol. 40, no. 21, pp. 2053-2058, 1987.

[19] S. A. Wohaieb and D. V. Godin, "Alterations in free radical tissue-defense mechanisms in streptozocin-induced diabetes in rat. Effects of insulin treatment," Diabetes, vol. 36, no. 9, pp. 1014-1018, 1987.

[20] D. R. Kapusta, S. Y. Jones, and G. F. DiBona, "Opioids in the systemic hemodynamic and renal responses to stress in conscious spontaneously hypertensive rats," Hypertension, vol. 13, no. 6, pp. 808-816, 1989.

[21] J. A. McCubbin, R. S. Surwit, R. B. Williams, C. B. Nemeroff, and M. McNeilly, "Altered pituitary hormone response to naloxone in hypertension development," Hypertension, vol. 14, no. 6, pp. 636-644, 1989.

[22] J. R. Naranjo, M. C. Urdin, J. Borrell, and J. A. Fuentes, "Evidence for a central but not adrenal, opioid mediation in hypertension induced by brief isolation in the rat," Life Sciences, vol. 38, no. 21, pp. 1923-1930, 1986.

[23] K. Eliasson, "Stress and catecholamines," Acta Medica Scandinavica, vol. 215, no. 3, pp. 197-204, 1984.

[24] I. M. Liu, C. S. Niu, T. C. Chi, D. H. Kuo, and J. T. Cheng, "Investigations of the mechanism of the reduction of plasma glucose by cold-stress in streptozotocin-induced diabetic rats," Neuroscience, vol. 92, no. 3, pp. 1137-1142, 1999.

[25] A. Ableitner and R. Schulz, "Neuroanatomical sites mediating the central actions of $\beta$-endorphin as mapped by changes in glucose utilization: involvement of mu opioid receptors," Journal of Pharmacology and Experimental Therapeutics, vol. 262, no. 1, pp. 415-423, 1992.

[26] S. Khan, A. A. L. Evans, S. Hughes, and M. E. Smith, “ $\beta$ endorphin decreases fatigue and increases glucose uptake independently in normal and dystrophic mice," Muscle and Nerve, vol. 31, no. 4, pp. 481-486, 2005.

[27] A. A. L. Evans, S. Khan, and M. E. Smith, "Evidence for a hormonal action of $\beta$-endorphin to increase glucose uptake in resting and contracting skeletal muscle," Journal of Endocrinology, vol. 155, no. 2, pp. 387-392, 1997.

[28] A. A. L. Evans, G. Tunnicliffe, P. Knights, C. J. Bailey, and M. E. Smith, "Delta opioid receptors mediate glucose uptake in skeletal muscles of lean and obese-diabetic (ob/ob) mice," Metabolism, vol. 50, no. 12, pp. 1402-1408, 2001.

[29] A. A. L. Evans and M. E. Smith, "Opioid receptors in fast and slow skeletal muscles of normal and dystrophic mice," Neuroscience Letters, vol. 366, no. 3, pp. 339-341, 2004.
[30] I.-M. Liu, T.-C. Chi, G.-C. Shiao, M.-T. Lin, and J.-T. Cheng, "Loss of plasma glucose lowering response to cold stress in opioid $\mu$-receptor knock-out diabetic mice," Neuroscience Letters, vol. 307, no. 2, pp. 81-84, 2001.

[31] R. Guillemin, T. Vargo, and J. Rossier, “ $\beta$ endorphin and adrenocorticotropin are secreted concomitantly by the pituitary gland," Science, vol. 197, no. 4311, pp. 1367-1369, 1977.

[32] S. J. Bunn, P. D. Marley, and B. G. Livett, "The distribution of opioid binding subtypes in the bovine adrenal medulla," Neuroscience, vol. 27, no. 3, pp. 1081-1094, 1988.

[33] M. T. Piascik, R. D. Guarino, M. S. Smith, E. E. Soltis, D. L. Saussy Jr., and D. M. Perez, "The specific contribution of the novel alpha-1D adrenoceptor to the contraction of vascular smooth muscle," Journal of Pharmacology and Experimental Therapeutics, vol. 275, no. 3, pp. 1583-1589, 1995.

[34] O. H. Viveros, E. J. Diliberto Jr., E. Hazum, and K. J. Chang, "Opiate-like materials in the adrenal medulla: evidence for storage and secretion with catecholamines," Molecular Pharmacology, vol. 16, no. 3, pp. 1101-1108, 1979.

[35] H. Y.T. Yang, A. M. Di Giulio, and W. Fratta, "Enkephalin in bovine adrenal gland: multiple molecular forms of [met $\left.{ }^{5}\right]$ enkephalin immunoreactive peptides," Neuropharmacology, vol. 19, no. 2, pp. 209-215, 1980.

[36] H. Furuta, "Direct evidence of $\alpha$-adrenoceptors binding in rat and human adrenal glands," Nippon Hinyokika Gakkai Zasshi, vol. 81, no. 2, pp. 161-169, 1990.

[37] J. T. Cheng, I. M. Liu, T. C. Chi, and T. F. Tzeng, "Release of $\beta$-endorphin by prostaglandin $\mathrm{E}_{2}$ to lower plasma glucose in streptozotocin-induced diabetic rats," Hormone and Metabolic Research, vol. 33, no. 7, pp. 439-443, 2001.

[38] J.-T. Cheng, I.-M. Liu, D.-H. Kuo, and M.-T. Lin, "Stimulatory effect of phenylephrine on the secretion of $\beta$-endorphin from rat adrenal medulla in vitro," Autonomic Neuroscience, vol. 93, no. 1-2, pp. 31-35, 2001.

[39] V. A. Arefolov, A. D. Dmitriev, A. V. Tennov, and A. V. Val'dman, "Detection of the pro-opiomelanocortin peptide fragments-beta-endorphin and $\mathrm{ACTH}$ - in the adrenals of rats and mice by immunohistochemistry," Biulleten' Eksperimental'noi Biologii i Meditsiny, vol. 101, no. 4, pp. 445-447, 1986.

[40] T. Mitsuma, T. Nogimori, D. H. Sun, and M. Chaya, "Thyrotropin-releasing hormone reduces the plasma levels of $\beta$-endorphin-like immunoreactivity in rats," Experimental and Clinical Endocrinology, vol. 89, no. 1, pp. 55-60, 1987.

[41] J. P. Hieble, D. B. Bylund, D. E. Clarke et al., "International union of pharmacology. X. Recommendation for nomenclature of $\alpha_{1}$-adrenoceptors: consensus update," Pharmacological Reviews, vol. 47, no. 2, pp. 267-270, 1995.

[42] K. P. Minneman, C. Han, and P. W. Abel, "Comparison of $\alpha 1$-adrenergic receptor subtypes distinguished by chlorethylclonidine and WB 4101," Molecular Pharmacology, vol. 33, no. 5, pp. 509-514, 1988.

[43] R. C. Smallridge, J. G. Kiang, I. D. Gist, H. G. Fein, and R. J. Galloway, "U-73122, an aminosteroid phospholipase C antagonist, noncompetitively inhibits thyrotropin-releasing hormone effects in GH3 rat pituitary cells," Endocrinology, vol. 131, no. 4, pp. 1883-1888, 1992.

[44] Y. Muto, T. Nagao, and T. Urushidani, "The putative phospholipase C inhibitor U73122 and its negative control, U73343, elicit unexpected effects on the rabbit parietal cell," Journal of Pharmacology and Experimental Therapeutics, vol. 282, no. 3, pp. 1379-1388, 1997. 
[45] J. M. Herbert, J. M. Augereau, J. Gleye, and J. P. Maffrand, "Chelerythrine is a potent and specific inhibitor of protein kinase C," Biochemical and Biophysical Research Communications, vol. 172, no. 3, pp. 993-999, 1990.

[46] D. Toullec, P. Pianetti, H. Coste et al., "The bisindolylmaleimide GF $109203 \mathrm{X}$ is a potent and selective inhibitor of protein kinase C," Journal of Biological Chemistry, vol. 266, no. 24, pp. 15771-15781, 1991.

[47] S. Cotecchia, D. A. Schwinn, R. R. Randall, R. J. Lefkowitz, M. G. Caron, and B. K. Kobilka, "Molecular cloning and expression of the cDNA for the hamster $\alpha 1$-adrenergic receptor," Proceedings of the National Academy of Sciences of the United States of America, vol. 85, no. 19, pp. 7159-7163, 1988.

[48] J. W. Lomasney, S. Cotecchia, W. Lorenz et al., "Molecular cloning and expression of the cDNA for the $\alpha_{1 \mathrm{~A}}$-adrenergic receptor: the gene for which is located on human chromosome 5," Journal of Biological Chemistry, vol. 266, no. 10, pp. 6365-6369, 1991.

[49] A. L. Morrow and I. Creese, "Characterization of $\alpha_{1}$ adrenergic receptor subtypes in rat brain: a reevaluation of $\left[{ }^{3} \mathrm{H}\right]$ WB4101 and $\left[{ }^{3} \mathrm{H}\right]$ prazosin binding," Molecular Pharmacology, vol. 29, no. 4, pp. 321-330, 1986.

[50] D. B. Bylund, D. C. Eikenberg, J. P. Hieble et al., "IV. International union of pharmacology nomenclature of adrenoceptors," Pharmacological Reviews, vol. 46, no. 2, pp. 121-136, 1994.

[51] A. P. D. W. Ford, T. J. Williams, D. R. Blue, and D. E. Clarke, " $\alpha 1$-adrenoceptor classification: sharpening Occam's razor," Trends in Pharmacological Sciences, vol. 15, no. 6, pp. 167170, 1994.

[52] I. Muramatsu, T. Taniguchi, and K. Okada, "Tamsulosin: $\alpha_{1}$-adrenoceptor subtype-selectivity and comparison with terazosin," Japanese Journal of Pharmacology, vol. 78, no. 3, pp. 331-335, 1998.

[53] H. Khachaturian, M. E. Lewis, K. Tsou, and S. J. Watson, “ $\beta$ endorphin, $\alpha$-MSH, ACTH and related peptides," in Handbook of Chemical Anatomy, A Björklund and T Hökfelt, Eds., vol. 4, pp. 216-72, Elsevier, Amsterdam, The Netherlands, 1985.

[54] M. Schultzberg, J. M. Lundberg, and T. Hokfelt, "Enkephalinlike immunoreactivity in gland cells and nerve terminals of the adrenal medulla," Neuroscience, vol. 3, no. 12, pp. 1169 1186, 1978.

[55] C.-T. Hsu, I.-M. Liu, and J.-T. Cheng, "Increase of $\beta$-endorphin biosynthesis in the adrenal gland of streptozotocin-induced diabetic rats," Neuroscience Letters, vol. 318, no. 2, pp. 57-60, 2002.

[56] C. Y. Cheung and F. Tang, "The effect of streptozotocindiabetes on $\beta$-endorphin level and proopiomelanocortin gene expression in the rat pituitary," Neuroscience Letters, vol. 261, no. 1-2, pp. 118-120, 1999.

[57] V. Law, L. C. Payne, and D. A. Weigent, "Effects of streptozotocin-induced diabetes on lymphocyte POMC and growth hormone gene expression in the rat," Journal of Neuroimmunology, vol. 49, no. 1-2, pp. 35-44, 1994.

[58] J. T. Cheng, I. M. Liu, T. F. Tzeng, C. C. Tsai, and T. Y. Lai, "Plasma glucose-lowering effect of $\beta$-endorphin in streptozotocin-induced diabetic rats," Hormone and Metabolic Research, vol. 34, no. 10, pp. 570-576, 2002.

[59] I.-M. Liu, T.-C. Chi, Y. C. Chen, F.-H. Lu, and J.-T. Cheng, "Activation of opioid $\mu$-receptor by ioperamide to lower plasma glucose in streptozotocin-induced diabetic rats," Neuroscience Letters, vol. 265, no. 3, pp. 183-186, 1999.
[60] J.-T. Cheng, I.-M. Liu, T.-C. Chi, T.-F. Tzeng, F.-H. Lu, and C. J. Chang, "Plasma glucose-lowering effect of tramadol in streptozotocin-induced diabetic rats," Diabetes, vol. 50, no. 12, pp. 2815-2821, 2001.

[61] A. Strother, J. K. Throckmorton, and C. Herzer, "The influence of high sugar consumption by mice on the duration of action of barbiturates and in vitro metabolism of barbiturates, aniline and p-nitroanisole," Journal of Pharmacology and Experimental Therapeutics, vol. 179, no. 3, pp. 490-498, 1971.

[62] A. Strother and L. S. K. Chau, "Influence of glucose (in vivo or in vitro) on duration of narcotic analgesics and on the kinetics of drug metabolism," Pharmacology, vol. 21, no. 3, pp. 161-166, 1980.

[63] B. A. Gosnell, M. Grace, C. J. Billington, and A. S. Levine, "Effects of streptozotocin-induced diabetes on feeding stimulated by centrally administered opioid agonists," Life Sciences, vol. 45, no. 1, pp. 31-40, 1989.

[64] G. S. Simon and W. L. Dewey, "Narcotics and diabetes. I. The effects of streptozotocin-induced diabetes on the antinociceptive potency of morphine," Journal of Pharmacology and Experimental Therapeutics, vol. 218, no. 2, pp. 318-323, 1981.

[65] J. Kamei, Y. Ohhashi, T. Aoki, N. Kawasima, and Y. Kasuya, "Streptozotocin-induced diabetes selectively alters the potency of analgesia produced by $\mu$-opioid agonists, but not by $\delta$ - and $\kappa$-opioid agonists," Brain Research, vol. 571, no. 2, pp. 199-203, 1992.

[66] P. K. Thomas, "Classification, differential diagnosis, and staging of diabetic peripheral neuropathy," Diabetes, vol. 46, no. 2, pp. S54-S57, 1997.

[67] S. Hughes, M. E. Smith, and C. J. Bailey, " $\beta$-endorphin and corticotropin immunoreactivity and specific binding in the neuromuscular system of obese-diabetic mice," Neuroscience, vol. 48, no. 2, pp. 463-468, 1992.

[68] S. Hughes, M. E. Smith, and C. J. Bailey, "POMC-derived peptides in the neuromuscular system of streptozotocindiabetic mice," Peptides, vol. 13, no. 5, pp. 873-877, 1992.

[69] J.-T. Cheng, I. M. Liu, T. C. Chi, and T. F. Tzeng, "Increase of opioid $\mu$-receptor gene expression in streptozotocin-induced diabetic rats," Hormone and Metabolic Research, vol. 33, no. 8, pp. 467-471, 2001.

[70] F. H. Ziel, N. Venkatesan, and M. B. Davidson, "Glucose transport is rate limiting for skeletal muscle glucose metabolism in normal and STZ-induced diabetic rats," Diabetes, vol. 37, no. 7, pp. 885-890, 1988.

[71] J. Berger, C. Biswas, P. P. Vicario, H. V. Strout, R. Saperstein, and P. F. Pilch, "Decreased expression of the insulinresponsive glucose transporter in diabetes and fasting," Nature, vol. 340, no. 6228, pp. 70-72, 1989.

[72] T. F. Tzeng, I. M. Liu, T. Y. Lai, C. C. Tsai, W. C. Chang, and J. T. Cheng, "Loperamide increases glucose ultilization in streptozotocin-induced diabetic rats," Clinical and Experimental Pharmacology and Physiology, vol. 30, no. 10, pp. 734-738, 2003.

[73] M. Bollen, S. Keppens, and W. Stalmans, "Specific features of glycogen metabolism in the liver," Biochemical Journal, vol. 336, no. 1, pp. 19-31, 1998.

[74] A. Consoli, N. Nurjhan, F. Capani, and J. Gerich, "Predominant role of gluconeogenesis in increased hepatic glucose production in NIDDM," Diabetes, vol. 38, no. 5, pp. 550-557, 1989. 
[75] W. Xie, G. M. Samoriski, J. P. McLaughlin et al., "Genetic alteration of phospholipase $C \beta 3$ expression modulates behavioral and cellular responses to $\mu$ opioids," Proceedings of the National Academy of Sciences of the United States of America, vol. 96, no. 18, pp. 10385-10390, 1999.

[76] I. M. Liu, S. S. Liou, W. C. Chen, P. F. Chen, and J. T. Cheng, "Signals in the activation of opioid $\mu$-receptors by loperamide to enhance glucose uptake into cultured C2C12 Cells," Hormone and Metabolic Research, vol. 36, no. 4, pp. 210-214, 2004.

[77] L. J. Goodyear, M. F. Hirshman, R. J. Smith, and E. S. Horton, "Glucose transporter number, activity, and isoform content in plasma membranes of red and white skeletal muscle," American Journal of Physiology, vol. 261, no. 5, pp. E556E561, 1991.

[78] W. I. Sivitz, S. L. DeSautel, T. Kayano, G. I. Bell, and J. E. Pessin, "Regulation of glucose transporter messenger RNA in insulin-deficient states," Nature, vol. 340 , no. 6228, pp. $72-$ $74,1989$.

[79] K. G. Mountjoy, G. M. Housey, and J. S. Flier, "Overproduction of the $\beta 1$ form of protein kinase $C$ enhances phorbol ester induction of glucose transporter mRNA," Molecular Endocrinology, vol. 3, no. 12, pp. 2018-2027, 1989.

[80] P. V. Attwood and D. B. Keech, "Pyruvate carboxylase," Current Topics in Cellular Regulation, vol. 23, pp. 1-55, 1984.

[81] R. W. Hanson and L. Reshef, "Regulation of phosphoenolpyruvate carboxykinase (GTP) gene expression," Annual Review of Biochemistry, vol. 66, pp. 581-611, 1997.

[82] J. M. Agati, D. Yeagley, and P. G. Quinn, "Assessment of the roles of mitogen-activated protein kinase, phosphatidylinositol 3-kinase, protein kinase $\mathrm{B}$, and protein kinase $\mathrm{C}$ in insulin inhibition of cAMP-induced phosphoenolpyruvate carboxykinase gene transcription," Journal of Biological Chemistry, vol. 273, no. 30, pp. 18751-18759, 1998.

[83] J.-T. Cheng and I.-M. Liu, "Stimulatory effect of caffeic acid on $\alpha(1 \mathrm{~A})$-adrenoceptors to increase glucose uptake into cultured C2C12 cells," Naunyn-Schmiedeberg's Archives of Pharmacology, vol. 362, no. 2, pp. 122-127, 2000.

[84] J. T. Cheng, I. M. Liu, T. F. Tzeng, W. C. Chen, S. Hayakawa, and T. Yamamoto, "Release of $\beta$-endorphin by caffeic acid to lower plasma glucose in streptozotocin-induced diabetic rats," Hormone and Metabolic Research, vol. 35, no. 4, pp. 251-258, 2003.

[85] F.-L. Hsu, Y.-C. Chen, and J.-T. Cheng, "Caffeic acid as active principle from the fruit of Xanthium strumarium to lower plasma glucose in diabetic rats," Planta Medica, vol. 66, no. 3, pp. 228-230, 2000.

[86] I.-M. Liu, W.-C. Chen, and J.-T. Cheng, "Mediation of $\beta$ endorphin by isoferulic acid to lower plasma glucose in streptozotocin-induced diabetic rats," Journal of Pharmacology and Experimental Therapeutics, vol. 307, no. 3, pp. 11961204, 2003.

[87] I.-M. Liu, T.-C. Chi, F.-L. Hsu, C.-F. Chen, and J.-T. Cheng, "Isoferulic acid as active principle from the rhizoma of Cimicifuga dahurica to lower plasma glucose in diabetic rats," Planta Medica, vol. 65, no. 8, pp. 712-714, 1999.

[88] I.-M. Liu, F.-L. Hsu, C.-F. Chen, and J.-T. Cheng, "Antihyperglycemic action of isoferulic acid in streptozotocin-induced diabetic rats," British Journal of Pharmacology, vol. 129, no. 4, pp. 631-636, 2000.

[89] I.-M. Liu, C.-C. Tsai, T.-Y. Lai, and J.-T. Cheng, "Stimulatory effect of isoferulic acid on $\alpha_{1 \mathrm{~A}}$-adrenoceptor to increase glucose uptake into cultured myoblast $\mathrm{C}_{2} \mathrm{C}_{12}$ cell of mice," Autonomic Neuroscience, vol. 88, no. 3, pp. 175-180, 2001.
[90] H.-H. Hsu, C.-K. Chang, H.-C. Su, I.-M. Liu, and J.-T. Cheng, "Stimulatory effect of puerarin on $\alpha 1 \mathrm{~A}$-adrenoceptor to increase glucose uptake into cultured $\mathrm{C}_{2} \mathrm{C}_{12}$ cells of mice," Planta Medica, vol. 68, no. 11, pp. 999-1003, 2002.

[91] F.-L. Hsu, I.-M. Liu, D.-H. Kuo, W.-C. Chen, H.-C. Su, and J.-T. Cheng, "Antihyperglycemic effect of puerarin in streptozotocin-induced diabetic rats," Journal of Natural Products, vol. 66, no. 6, pp. 788-792, 2003.

[92] W.-C. Chen, S. Hayakawa, T. Yamamoto, H.-C. Su, I.M. Liu, and J.-T. Cheng, "Mediation of $\beta$-endorphin by the isoflavone puerarin to lower plasma glucose in streptozotocin-induced diabetic rats," Planta Medica, vol. 70, no. 2, pp. 113-116, 2004.

[93] B. C. Yu, C. K. Chang, C. F. Su, and J. T. Cheng, "Mediation of $\beta$-endorphin in andrographolide-induced plasma glucoselowering action in type I diabetes-like animals," NaunynSchmiedeberg's Archives of Pharmacology, vol. 377, no. 4-6, pp. 529-540, 2008.

[94] B.-C. Yu, C.-R. Hung, W.-C. Chen, and J.-T. Cheng, "Antihyperglycemic effect of andrographolide in streptozotocininduced diabetic rats," Planta Medica, vol. 69, no. 12, pp. 1075-1079, 2003.

[95] J.-H. Hsu, S.-S. Liou, B.-C. Yu, J.-T. Cheng, and Y.-C. $\mathrm{Wu}$, "Activation of $\alpha 1 \mathrm{~A}$-adrenoceptor by andrographolide to increase glucose uptake in cultured myoblast C2C12 cells," Planta Medica, vol. 70, no. 12, pp. 1230-1233, 2004.

[96] I.-M. Liu, S.-S. Liou, and J.-T. Cheng, "Mediation of $\beta$-endorphin by myricetin to lower plasma glucose in streptozotocin-induced diabetic rats," Journal of Ethnopharmacology, vol. 104, no. 1-2, pp. 199-206, 2006.

[97] I.-M. Liu, S.-S. Liou, T.-W. Lan, F.-L. Hsu, and J.-T. Cheng, "Myricetin as the active principle of Abelmoschus moschatus to lower plasma glucose in streptozotocin-induced diabetic rats," Planta Medica, vol. 71, no. 7, pp. 617-621, 2005.

[98] D.-M. Lai, Y.-K. Tu, I.-M. Liu, P.-F. Chen, and J.-T. Cheng, "Mediation of $\beta$-endorphin by ginsenoside Rh2 to lower plasma glucose in streptozotocin-induced diabetic rats," Planta Medica, vol. 72, no. 1, pp. 9-13, 2006.

[99] H.-S. Niu, F.-L. Hsu, I.-M. Liu, and J.-T. Cheng, "Increase of $\beta$-endorphin secretion by syringin, an active principle of Eleutherococcus senticosus, to produce antihyperglycemic action in type 1-like diabetic rats," Hormone and Metabolic Research, vol. 39, no. 12, pp. 894-898, 2007.

[100] H.-S. Niu, I.-M. Liu, J.-T. Cheng, C.-L. Lin, and F.-L. $\mathrm{Hsu}$, "Hypoglycemic effect of syringin from Eleutherococcus senticosus in streptozotocin-induced diabetic rats," Planta Medica, vol. 74, no. 2, pp. 109-113, 2008.

[101] M. N. Clifford, "Chlorogenic acids and other cinnamatesnature, occurrence and dietary burden," Journal of the Science of Food and Agriculture, vol. 79, no. 3, pp. 362-372, 1999.

[102] E. Graf, "Antioxidant potential of ferulic acid," Free Radical Biology and Medicine, vol. 13, no. 4, pp. 435-448, 1992.

[103] Y. Ozaki and J.-P. Ma, "Inhibitory effects of tetramethylpyrazine and ferulic acid on spontaneous movement of rat uterus in situ," Chemical and Pharmaceutical Bulletin, vol. 38, no. 6, pp. 1620-1623, 1990.

[104] M. Bakovic and H. B. Dunford, "Oxidation kinetics of caffeic acid by prostaglandin $\mathrm{H}$ synthase: potential role in regulation of prostaglandin biosynthesis," Prostaglandins Leukotrienes and Essential Fatty Acids, vol. 51, no. 5, pp. 337-345, 1994.

[105] Y.-F. Chen, H.-Y. Tsai, and T.-S. Wu, "Anti-inflammatory and analgesic activities from roots of Angelica pubescens," Planta Medica, vol. 61, no. 1, pp. 2-8, 1995. 
[106] W. M. Keung and B. L. Vallee, "Kudzu root: an ancient Chinese source of modern antidipsotropic agents," Phytochemistry, vol. 47, no. 4, pp. 499-506, 1998.

[107] Q. Liu, Z. Lu, and L. Wang, "Restrictive effect of puerarin on myocardial infarct area in dogs and its possible mechanism," Journal of Tongji Medical University, vol. 20, no. 1, pp. 43-45, 2000.

[108] M. C. Guerra, E. Speroni, M. Broccoli et al., "Comparison between Chinese medical herb Pueraria lobata crude extract and its main isoflavone puerarin: antioxidant properties and effects on rat liver CYP-catalysed drug metabolism," Life Sciences, vol. 67, no. 24, pp. 2997-3006, 2000.

[109] X. R. Lu, E. Gao, L. Z. Xu et al., "Puerarin beta-adrenergic receptor blocking effect," Chinese Medical Journal, vol. 100, no. 1, pp. 25-8, 1987.

[110] A. Basak, S. Cooper, A. G. Roberge, U. K. Banik, M. Chrétien, and N. G. Seidah, "Inhibition of proprotein convertases-1, -7 and furin by diterpines of Andrographis paniculata and their succinoyl esters," Biochemical Journal, vol. 338, no. 1, pp. 107-113, 1999.

[111] P. K. S. Visen, B. Shukia, G. K. Patnaik, and B. N. Dhawan, "Andrographolide protects rat hepatocytes against paracetamol-induced damage," Journal of Ethnopharmacology, vol. 40, no. 2, pp. 131-136, 1993.

[112] A. Kapil, I. B. Koul, S. K. Banerjee, and B. D. Gupta, "Antihepatoxic effects of major diterpenoid constituents of Andrographis paniculata," Biochemical Pharmacology, vol. 46, no. 1, pp. 182-185, 1993.

[113] S. S. Handa and A. Sharma, "Hepatoprotective activity of Andrographolide from andrographis paniculata against carbontetrachloride," Indian Journal of Medical Research, vol. 92, pp. 276-283, 1990.

[114] A. Puri, R. Saxena, R. P. Saxena, K. C. Saxena, V. Srivastava, and J. S. Tandon, "Immunostimulant agents from Andrographis paniculata," Journal of Natural Products, vol. 56, no. 7, pp. 995-999, 1993.

[115] W.-F. Chiou, C.-F. Chen, and J.-J. Lin, "Mechanisms of suppression of inducible nitric oxide synthase (iNOS) expression in RAW 264.7 cells by andrographolide," British Journal of Pharmacology, vol. 129, no. 8, pp. 1553-1560, 2000. 


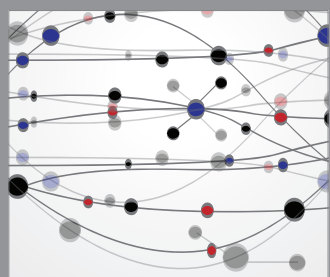

The Scientific World Journal
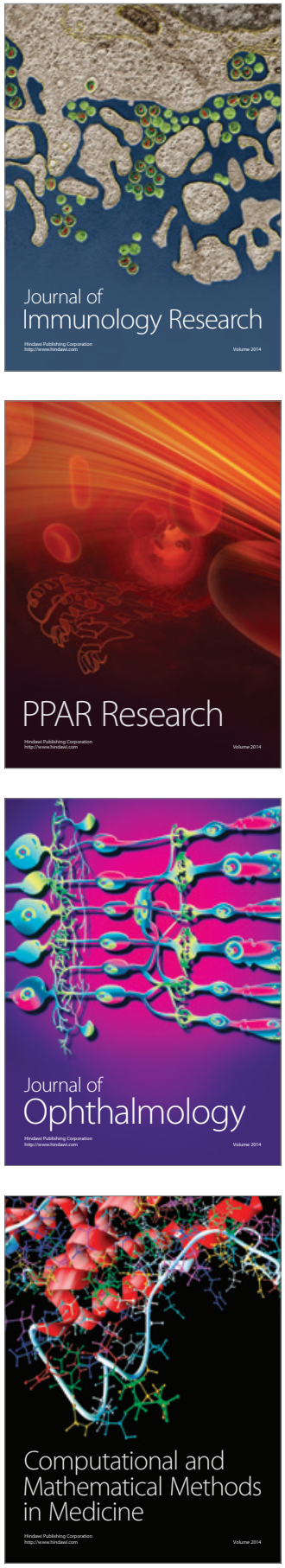

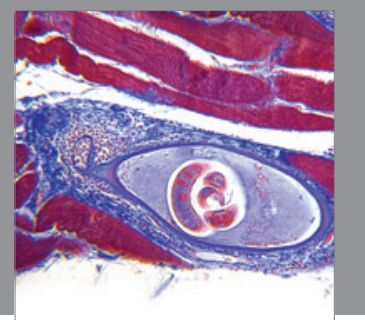

Gastroenterology

Research and Practice
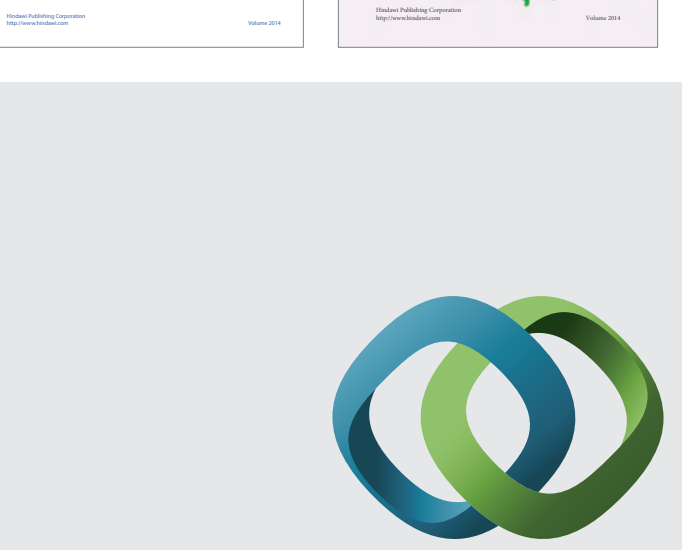

\section{Hindawi}

Submit your manuscripts at

http://www.hindawi.com
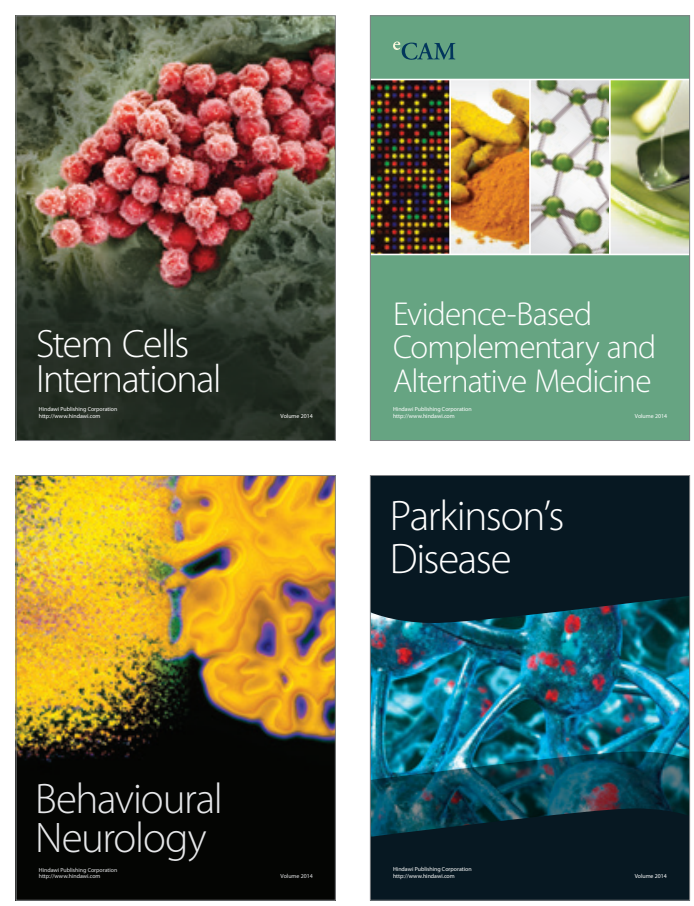

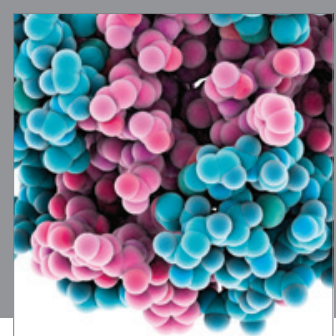

Journal of
Diabetes Research

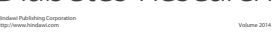

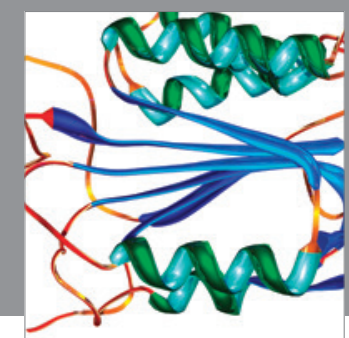

Disease Markers
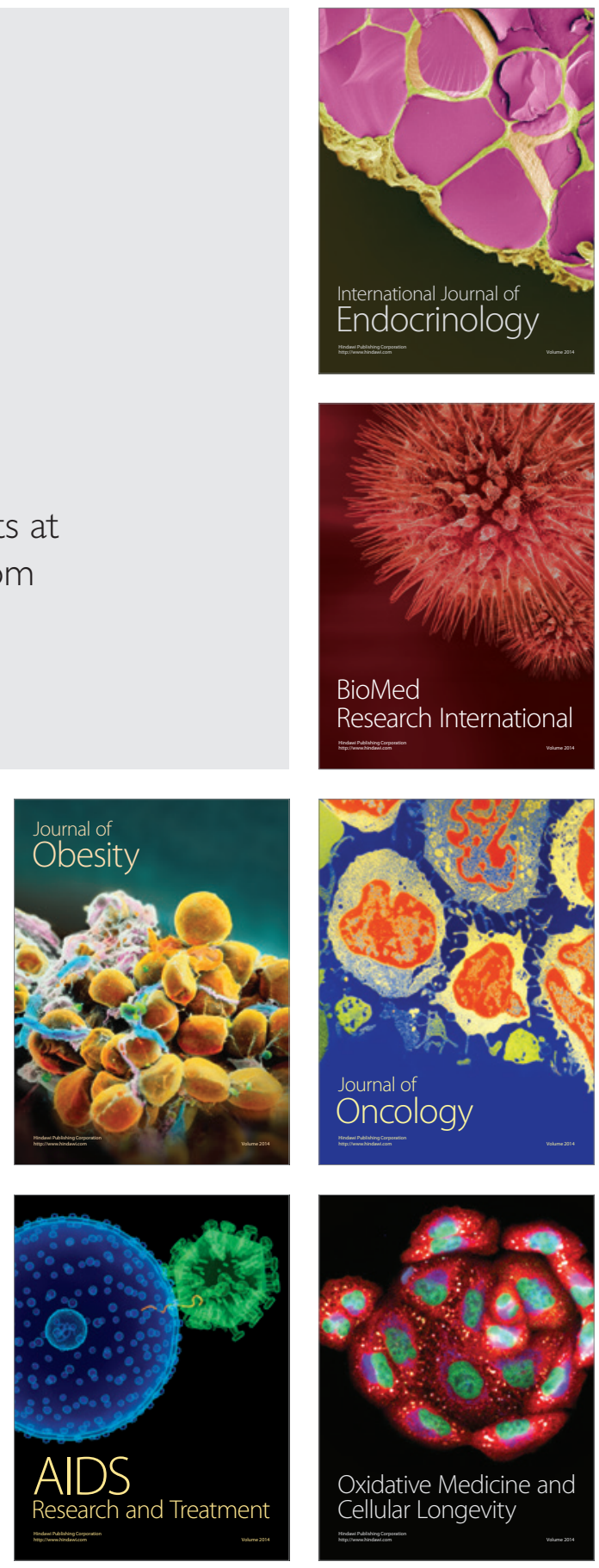